\title{
Scaling of Wear Resistance of Rubber Compounds for Tires Using Rubber Properties
}

Michio HIRAYAMA ${ }^{1,2^{*}}$, Takashi NISHINO ${ }^{2}\left({ }^{1}\right.$ Sumitomo Rubber Industries, LTD., Tsutsui,Chuo,Kobe 651-0071,Japan. ${ }^{2}$ Department of Chemical Science and Engineering, Graduate School of Engineering, Kobe University, Rokko, Nada, Kobe 657-8501, Japan)*m-hirayama.az@srigroup.co.jp

The tire wear tests were performed for rubber compounds with different physical properties on the different road surface temperature using the same vehicle. It is clear that the temperature dependence of wear resistance were different for the different rubber compounds. The wear resistance $W$ is found to be scaled using the fracture energy $F$ $\left(\mathrm{MJ} / \mathrm{m}^{3}\right)$ and the storage modulus $E^{*}(\mathrm{MPa})$ for the rubber compound as follows:

$W=c\left(F^{a} / E^{* b}\right)(a, b, c=$ the constant number $)$

Temperature dependence of wear resistance is considered to be caused by the different contribution of $F$ and $E^{*}$ values.

(Received on September 21, 2012) (Accepted on December 10, 2012)

Key Words : Wear resistance, Tire, Rubber compound, Scaling

1. 緒言

耐摩耗性能は夕イヤの重要な基本性能のひとつであり, 制動性能, 低燃費性能とのバランスが求められている中, 省資源化および経済性の観点からタイヤの耐摩耗性能を確 保することは重要である。この際, 耐摩耗性能に影響する 因子は多岐にわたっており，摩耗現象そのものが複雑であ るために予測には困難を伴う ${ }^{1-4)}$.

Figure 1 には, 耐摩耗性能に影響する主要な要因を挙げ た。これらの影響のうち, 特に温度についてはコンパウン ドの種類により受ける影響の程度が異なる。摩耗の温度依 存性はゴムのいずれの特性と相関があるのかについては不

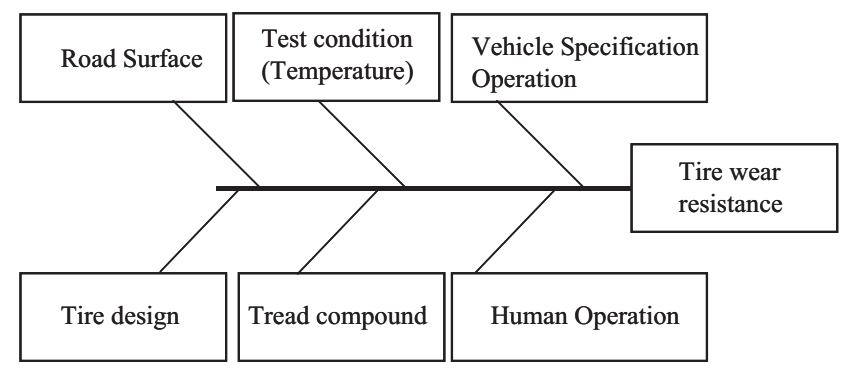

Figure 1 Factors effect on tire wear resistance.

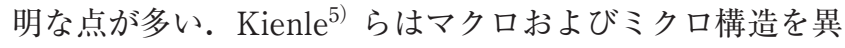
にする 12 種類のポリマーを用いたガラス転移温度（以下 $\mathrm{Tg}$ と略す）を異にする配合について, 実車摩耗テストを 行い, Tg と耐摩耗性能との間に高い相関を示すことを明 らかにした。この際, 夏と冬で耐摩耗性能が異なるデータ を得ているが，その理由についての言及がなく，耐摩耗性 能のメカニズムは必ずしも明らかになっていない. Veith ${ }^{6)}$ らは10種類の異なる配合について, 実車摩耗テストを実 施し, E摩耗と P 摩耗という2 通りの摩耗機構の存在を提 唱した。E摩耗およびP摩耗の変形挙動を模式的に Figure 2 に示した。 E摩耗はゴムが突起に粘着して弾性変形し, 限界の摩擦力に達すると滑るという変形挙動である.ここ で弾性を意味する“Elastic”の頭文字をとってE摩耗と名
Figure 2-a) E-wear

Rubber (Soft)

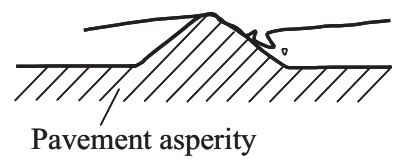
proposed by Veith ${ }^{6}$.
Figure 2-b) P-wear

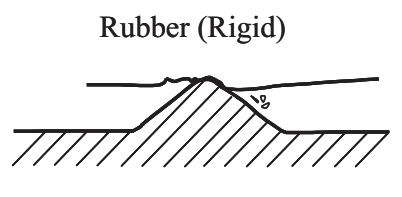

Figure 2 Schematic diagrams of a) 'E-wear' and b) 'P-wear' proposed by Veith 
づけられている. E摩耗は過酷度の高い場合の摩耗であり, ゴムが大きく変形する場合，すなわち高温で生じるとされ ている。これに対してP摩耗は突起に沿ってゴムが滑る様 相を表し，このときゴムは変形せずに引っ掻かれて破壊に 至る挙動である。この場合，ゴムは硬くプラスチックのよ うに挙動することから “Plastic”の頭文字をとって P摩耗 と呼ばれている。P摩耗は過酷度の低い時の摩耗であり, 低温時の変化に対応する。しかしながら, Veithらもこれ らの摩耗現象についてゴムの物性を用いた定量的な解析を 進めておらず，耐摩耗性能と物性の関連性については検討 の余地がある.

今回われわれは，トレッドゴムの種類を異にする夕イヤ を用いて路面温度が異なる時期に実車摩耗評価を行い，耐 摩耗性能の温度依存性について検討を行った。また，各種 ゴム物性と耐摩耗性能の関連性について検討した。

\section{2. 実 験 方 法}

\section{1 試料}

Table 1 に本実験で用いたタイヤのトレッドゴムの配合 を示した。ゴム成分として天然ゴム（NR）に対してTg を異にするスチレンブタジエンゴム (SBR)，ポリブタジ エンゴム（BR）を配合し，これらの配合に加硫促進剂と 硫黄等をそれぞれ配合した。

\section{2 試料作製}

加硫剤以外のゴム成分，補強剤としてのカーボンブラッ ク，シリカ，加工助剤などをミキサー (株) KOBELCO 製 MIXTRON BB）に投入した。ミキサーの回転数は 115 $\mathrm{rpm}$ で，検出トルクが一定になるまで混練した。多くの 場合，排出温度は $160{ }^{\circ} \mathrm{C}$ で，混練り時間は 5 分であった。 ミキサーで混練したベースゴムに，オープンロール（関西 ロール(株)製 8 インチロール）にて，ゴム温度が 110 ㅇ以下 にて，硫黄および加硫促進剤を4分間混練した。

得られた未加硫ゴムシートを用いて，厚さ $10 \mathrm{~mm}$ のト レッドの形状に成形し, 他のタイヤ部位と貼り合わせ,

Table 1 Formulation of rubber compounds in phr.

\begin{tabular}{|c|c|c|c|c|}
\hline Recipe $\quad$ Name & $\mathrm{A}$ & $\mathrm{B}$ & $\mathrm{C}$ & $\mathrm{D}$ \\
\hline NR & 30 & 30 & 20 & 40 \\
\hline SBR (1) $\mathrm{Tg}=-16^{\circ} \mathrm{C}$ & 70 & & & \\
\hline SBR (2) $\mathrm{Tg}=-12^{\circ} \mathrm{C}$ & & 70 & & \\
\hline $\mathrm{SBR}$ (3) $\mathrm{Tg}=-22^{\circ} \mathrm{C}$ & & & 52 & \\
\hline $\mathrm{SBR}$ (4) $\mathrm{Tg}=-25^{\circ} \mathrm{C}$ & & & & 60 \\
\hline $\mathrm{BR}$ & & & 28 & \\
\hline Carbon Black (ISAF) & 33 & 7 & 37 & \\
\hline Carbon Black (HAF) & & & & 62 \\
\hline Silica & 23 & 60 & 56 & \\
\hline Process Oil & 23 & 15 & 38 & 18 \\
\hline
\end{tabular}

$170{ }^{\circ} \mathrm{C}$ で 12 分間加硫することにより，試験用夕イヤ（夕 イヤサイズ：195/65R15）を作製した。

各種物性の測定に供するサンプルとして，上記未加硫ゴ ムシートを用いて $170{ }^{\circ} \mathrm{C} ， 12$ 分間加硫することにより平 板状の加硫シート（厚さ $2 \mathrm{~mm} ）$ を作製した.

\section{3 測定}

\subsection{1 実車摩耗試験}

同一車両を使用し，トレッドゴムを異にする4種類（配 合 $\mathrm{A} \sim \mathrm{D})$ の夕イヤを用い，気温が異なる時期に実車摩耗 試験を実施した。実車摩耗試験の時期として，7月（平均 気温 $21{ }^{\circ} \mathrm{C}$, 平均路面温度 $27^{\circ} \mathrm{C}$ ) と 11 月 (平均気温 $7{ }^{\circ} \mathrm{C}$, 平均路面温度 $7^{\circ} \mathrm{C}$ ) に実施した。試験方法として, 高速道 路，一般道路，山岳路を織り交ぜ， $8000 \mathrm{~km}$ 走行させた後 のタイヤ主溝の残溝を測定することにより摩耗量とした. ここで耐摩耗係数としてタイヤを $1 \mathrm{~mm}$ 摩耗させるのに必 要な走行距離 $(\mathrm{km})$ と定義した。

\subsection{2 粘弾性試験}

(株)岩本製作所製粘弾性スペクトロメーター（TYPE VES-F-III）を用いて測定を実施した。試験片の寸法は， 幅 $4 \mathrm{~mm}$, 厚さ $2 \mathrm{~mm}$, 長さ $40 \mathrm{~mm}$ である. 試験片を保持 するチャック間距離は $30 \mathrm{~mm}$ とした。静的な初期伸張を $10 \%$ 与えた状態で，0.5\%の動的歪を周波数 $10 \mathrm{~Hz}$ で与え， 昇温速度 $3{ }^{\circ} \mathrm{C} /$ 分にて， $-70 \sim 50{ }^{\circ} \mathrm{C}$ の範囲内で貯蔵弾性 率 $E^{*}$ および損失正接 $\tan \delta$ の測定を行った. $\tan \delta$ のピー ク温度を $\mathrm{Tg}$ の評価指標とした。

\subsection{3 引張試験}

引張試験機として(株島津製作所製オートグラフ AGS-J を用いて，JIS K6251「加硫ゴム及び熱可塑性ゴム一引張 特性の求め方」に準ずる方法にて測定を行った。試験片の 形状は，ダンベル状 3 号形で，試験片つかみ具の移動速度 は， $500 \mathrm{~mm} /$ 分である。試験温度は，-40，-10，0，23 ${ }^{\circ} \mathrm{C}$ とした，各測定温度において応力ーひずみ曲線とひずみ 軸で囲まれる面積から破壊エネルギー $F\left(\mathrm{MJ} / \mathrm{m}^{3}\right)$ を求め た。

\section{3. 実 験 結 果}

\section{1 実車摩耗試験}

Table 2 には, 加硫ゴムの Tg, 夏期および冬期に実施し た実車摩耗テストの結果を示した。配合 Bでは低温と高温 の耐摩耗係数の差が大きい。一方，配合 Bに比較して配合 Cの耐摩耗係数の温度依存性が少なく，低温および高温の いずれの条件下においても耐摩耗係数が高かった。また， 配合 D は配合 A と Cの中間的な位置づけにある。この様 に，配合に依存して耐摩耗係数の温度依存性の傾向が異な ることが示された。

\section{2 動的粘弾性試験および引張試験}

Figure 3 には, 配合 $\mathrm{A} \sim \mathrm{D}$ の加硫ゴムの貯蔵弾性率の 
Table 2 Tg and wear resistance of rubber compound A-D.

\begin{tabular}{lcccc}
\hline Rubber compound & A & B & C & D \\
\hline Tg $\left({ }^{\circ} \mathrm{C}\right)$ & -16.0 & -10.7 & -32.9 & -31.4 \\
Wear Resistance $(\mathrm{km} / \mathrm{mm}) @$ Summer $^{\text {a) }}$ & 11630 & 12960 & 13780 & 12100 \\
Wear Resistance $(\mathrm{km} / \mathrm{mm}) @$ Winter $^{\mathrm{b})}$ & 10350 & 10040 & 13920 & 12640 \\
\hline
\end{tabular}

a) Temperature of the road surface $: 27^{\circ} \mathrm{C}$

b) Temperature of the road surface : $7{ }^{\circ} \mathrm{C}$

温度依存性を示した。配合 C，Dに比較して，配合 A，B は Tgが高く, - $10{ }^{\circ} \mathrm{C}$ 以下の温度領域で貯蔵弾性率が高 かった。これは配合の主成分となる SBRの Tgを反映した 結果と考えられる。

Figure 4には，配合 A〜Dの加硫ゴムの破壊エネルギ 一の温度依存性を示した．配合Cでは全ての温度条件で高 い破壊エネルギーを示した。配合 C，Dに比較して，配合 A，Bでは特にー $40{ }^{\circ} \mathrm{C}$ の破壊エネルギーが低かった。こ れは $\mathrm{Tg}$ 以下の温度でゴムの破断伸度が低下したことに基

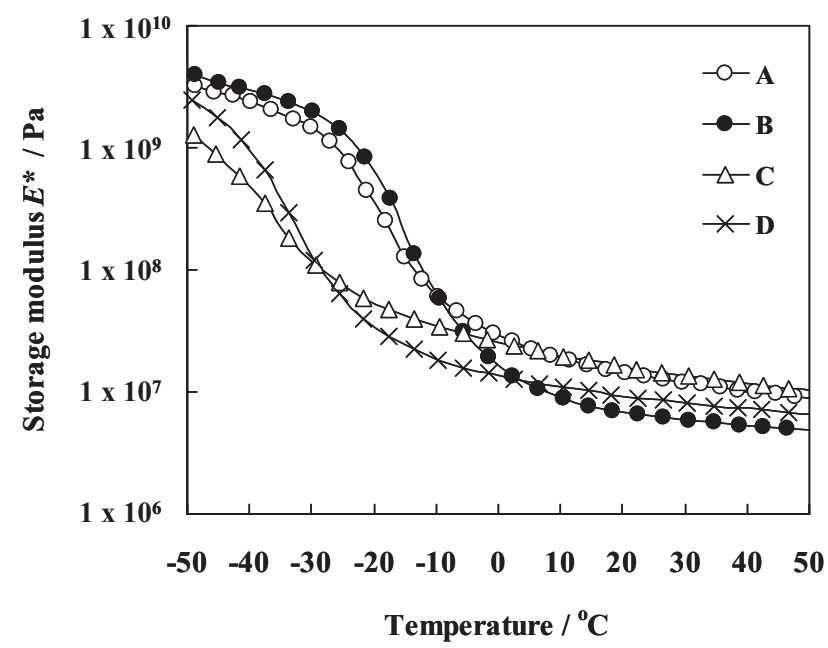

Figure 3 Temperature dependence of storage modulus $E^{*}$ of rubber compound A-D.

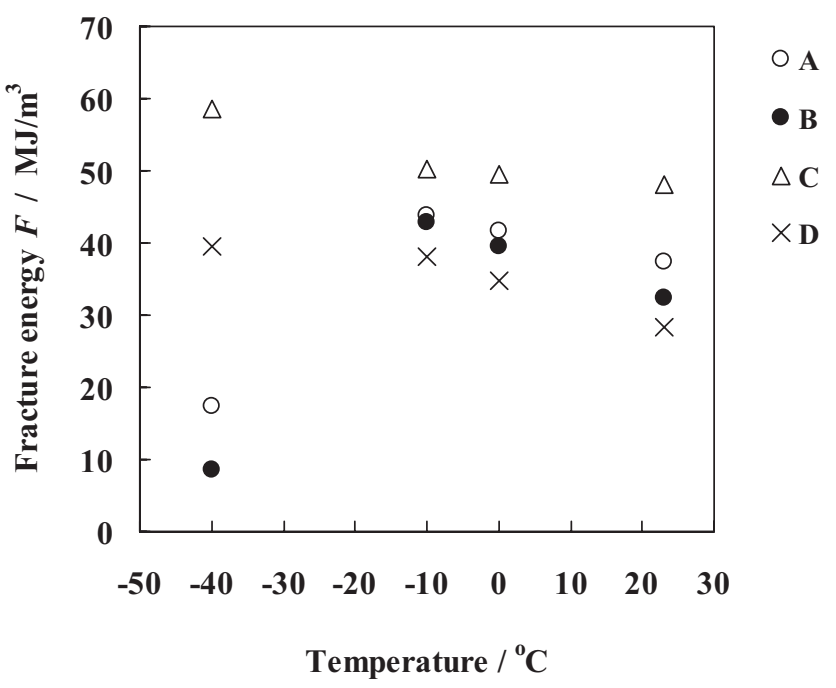

Figure 4 Temperature dependence of fracture energy of rubber compound A-D.
づいた.

\section{4. 考察}

Figure 5には，路面骨材の凹凸で変形しているゴムを模 式的に示した。ここで，路面とゴムの接触面積 $M$ が大き いほど，単位面積あたりにかかるせん断力を小さくするこ とができ，摩耗が抑制されるとして，耐摩耗係数 $W$ との 間に次式を仮定した。

$$
W=f(M)
$$

Moore ${ }^{7)}$ らは，Mがゴム材料の貯蔵弾性率 $E^{*}$ に反比例 すると報告していることから，（1）式は次の（2）式で示 される。

$$
W=f\left(E^{*-1}\right)
$$

また, Grosch $^{8)}$ およびPulford ${ }^{9)}$ らは摩耗と破壞特性につ いて, 引張破断エネルギーとの相関を報告している，摩耗 はゴムの破壊現象であることから，破壊エネルギー $F$ が高 ければゴムの耐摩耗性能は増加することから，（3）式の相 関が与えられる。

$$
W=f(F)
$$

以上の因子を組み合わせると $W$ は（4）式でスケーリング することができる.

$$
W=c\left(F^{a} / E^{*} b\right) \quad(a, b, c \text { は定数 })
$$

（4）式を対数表示に変形すると

$$
\log W=a \log F-b \log E^{*}+\log c
$$

と表せる.

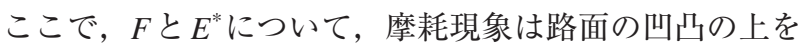
速い速度ですべって扔り路面の表面から変形を受ける現象 である。この際，ゴムが受ける変形の周波数は $10^{4} \sim$ $10^{6} \mathrm{~Hz}$ 程度と言われている ${ }^{10)}$. Groschらはゴム物性に対 して時間－温度換算則が成り立つことを示している ${ }^{11)}$. そこで，低温の破壊エネルギー $F$ 抢上び弾性率 $E^{*}$ と耐摩

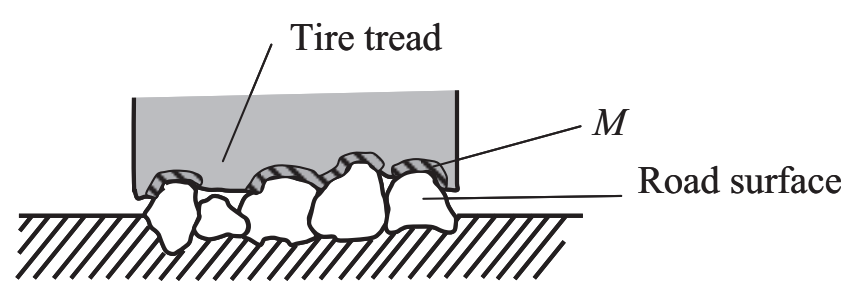

Figure 5 Schematic of tire tread surface in contact with rough road surface. 
耗係数 $W$ の相関性について検討を行い，それらの物性值 で実車摩耗評価結果が説明できるかの検証を行った。

ここでFigure 3，4で示したように，Fと $E^{*}$ は温度依存 性を示しており，いずれの温度領域の数值を用いて $W$ を 評価するかを検討するため， $W に$ 対しての $F$ および $E^{*} の$ 相 関分析を行った。

一般に，yに対する $\mathrm{x}$ の相関係数 $\mathrm{R}$ は，以下のように得 られる。

$(\mathrm{x}, \mathrm{y})=\left\{\left(\mathrm{x}_{i,} \mathrm{y}_{i}\right)\right\} \quad(i=1,2, \ldots, \mathrm{n})$ が与えられたとき,

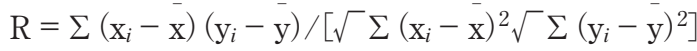

ただし，x，yはそれぞれのデー夕の相加平均である.

得られた結果を Table 3 に示した。夏期の $W$ 值は $0{ }^{\circ} \mathrm{C} の$ $F$ と, 冬期の $W$ 值は $-40{ }^{\circ} \mathrm{C} の ~ F$ と $E^{*}$ と高い相関性を示し た。すなわち，実車摩耗試験結果が，実際の路面よりも低 い温度でのゴム物性と相関することが明らかになった。こ のように摩耗と関連があるゴムの物性の温度領域が，低温 側にシフトするのは，摩耗現象が路面の凹凸の上を速い速 度ですべっており，上述のように時間－温度換算則が関与 したためと考えられる。

次に，耐摩耗係数 $W$ と $F$ および $E$ *関係性を検討する ため，(5）式を重回帰式とし,夏の耐摩耗係数 $\log W @ S u m-$ merを目的変数とし, $0{ }^{\circ} \mathrm{C}$ の $\log E^{*}$ と $\log F$ を説明変数とし て， $a, b, c$ を最適化する重回帰分析を実施した ${ }^{12)}$.

すなわち，(5) 式を（7）式のとおり簡略化すると，

$\mathrm{y}=\mathrm{A}+\mathrm{B}_{1} \mathrm{x}_{1}+\mathrm{B}_{2} \mathrm{x}_{2}$

ここで, $\mathrm{y}=\log W, \mathrm{~A}=\log c, \quad \mathrm{~B}_{1}=a, \mathrm{x}_{1}=\log F, \quad \mathrm{~B}_{2}=-$ $\mathrm{b}, \mathrm{x}_{2}=\log E^{*}$ を示している.

実測值 $\mathrm{y}_{\text {obe }}$ は理論值 $\mathrm{y}_{\text {est }}$ との残差 $e$ の和であることから 次式が与えられる。

$\mathrm{y}_{\text {obe }}=\mathrm{y}_{\text {est }}+e$

ここで残差 $e$ の 2 乗の総和（残差平方和 RSS）を最小に するように（9）式を用いて係数を求める.
$\operatorname{MinRSS}=\sum(e)^{2}=\left(\mathrm{y}_{\text {obs }}-\mathrm{y}_{\mathrm{est}}\right)^{2}=\sum\left(\mathrm{y}_{\mathrm{obs}}-\mathrm{A}-\mathrm{B}_{1} \mathrm{x}_{1}-\right.$ $\left.\mathrm{B}_{2} \mathrm{x}_{2}\right)^{2}$

RSSを $\mathrm{A}, \mathrm{B}_{1}, \mathrm{~B}_{2}$ で微分して0 とすると

$\sum\left(\mathrm{Y}_{\mathrm{obs}}-\mathrm{A}-\mathrm{B}_{1} \mathrm{x}_{1}-\mathrm{B}_{2} \mathrm{x}_{2}\right)^{2}=0$

したがって，下記の正規方程式が得られる.

Tをデー夕の標本数とすると

$\sum \mathrm{y}_{\mathrm{t}}=\mathrm{TA}+\mathrm{B}_{1} \sum \mathrm{x}_{1 \mathrm{t}}+\mathrm{B}_{2} \sum \mathrm{x}_{2 \mathrm{t}}$

$\sum \mathrm{x}_{1 \mathrm{t}} \mathrm{y}_{\mathrm{t}}=\mathrm{A} \sum \mathrm{x}_{1 \mathrm{t}}+\mathrm{B}_{1} \sum \mathrm{x}_{1 \mathrm{t}}^{2}+\mathrm{B}_{2} \sum \mathrm{x}_{1 \mathrm{t}} \mathrm{x}_{2 \mathrm{t}}$

$\sum \mathrm{x}_{2 \mathrm{t}} \mathrm{y}_{\mathrm{t}}=\mathrm{A} \sigma \mathrm{x}_{2 \mathrm{t}}+\mathrm{B}_{1} \sum \mathrm{x}_{1 \mathrm{t}} \mathrm{x}_{2 \mathrm{t}}+\mathrm{B}_{2} \sum \mathrm{x}_{2 \mathrm{t}}{ }^{2}$

これら正規方程式を解いて

$\mathrm{A}=\mathrm{y}-\mathrm{B}_{1} \mathrm{x}_{1}-\mathrm{B}_{2} \mathrm{x}_{2}$

$\mathrm{B}_{1}=\left(\mathrm{S}_{2}^{2} \mathrm{~S}_{1 \mathrm{y}}-\mathrm{S}_{12} \mathrm{~S}_{2 \mathrm{y}}\right) /\left(\mathrm{S}_{1}^{2} \mathrm{~S}_{2}{ }^{2}-\mathrm{S}_{12}{ }^{2}\right)$

$\mathrm{B}_{2}=\left(\mathrm{S}_{1}^{2} \mathrm{~S}_{2 \mathrm{y}}-\mathrm{S}_{12} \mathrm{~S}_{1 \mathrm{y}}\right) /\left(\mathrm{S}_{1}^{2} \mathrm{~S}_{2}^{2}-\mathrm{S}_{12}{ }^{2}\right)$

ただし，

$\mathrm{S}_{1}^{2}=\sum\left(\mathrm{x}_{1 \mathrm{t}}-\overline{\mathrm{x}}_{1}\right)^{2}, \mathrm{~S}_{2}^{2}=\sum\left(\mathrm{x}_{2 \mathrm{t}}-\overline{\mathrm{x}}_{2}\right)^{2}$,

$\mathrm{S}_{\mathrm{y}}^{2}=\sum\left(\mathrm{y}_{\mathrm{t}}-\mathrm{y}\right)^{2}$,

$\mathrm{S}_{12}{ }^{2}=\sum\left(\mathrm{x}_{1 \mathrm{t}}-\mathrm{x}_{1}\right) \quad\left(\mathrm{x}_{2 \mathrm{t}}-\mathrm{x}_{2}\right)$,

$\mathrm{S}_{1 \mathrm{y}}{ }^{2}=\sum\left(\mathrm{x}_{1 \mathrm{t}}-\mathrm{x}_{1}\right) \quad\left(\mathrm{y}_{\mathrm{t}}-\mathrm{y}\right)$,

$\mathrm{S}_{2 \mathrm{y}}{ }^{2}=\sum\left(\mathrm{x}_{2 \mathrm{t}}-\mathrm{x}_{2}\right) \quad\left(\mathrm{y}_{\mathrm{t}}-\mathrm{y}\right)$

以上より, $a, b, c$ を求めることができる.

同様に，耐摩耗係数logW@Winterを目的変数とし て， $-40{ }^{\circ} \mathrm{C}$ の $\log E^{*}$ と $\log F$ を説明変数として，重回帰分 析を実施した。

この解析により（5）式における係数を設定することが 可能となり，予測式を決定することができる.

Figure 6 には，重相関解析で得られた予測式と実車摩耗 テスト結果の関係を示した。図より実車の耐摩耗係数と

(5) 式から予測できる耐摩耗係数の間には高い相関性が観 察された. Table 4 には, 得られた重相関係数を示した。 夏期および冬期それぞれで高い重相関係数が得られた。こ のことは，(5) 式を用いて今回の実車摩耗テスト結果をス ケーリングできることを意味している，すなわち，冬期の

Table 3 Correlation coefficients between the observed wear resistance and physical properties $F, E^{*}$ at each temperature.

\begin{tabular}{ccc}
\hline Physical property & Wear resistance@Summer & Wear resistance@Winter \\
\hline$F @-40^{\circ} \mathrm{C}$ & 0.293 & $0.964++$ \\
$F @-10^{\circ} \mathrm{C}$ & $0.676+$ & 0.294 \\
$F @ 00^{\circ} \mathrm{C}$ & $0.640+$ & 0.350 \\
$F @ 23^{\circ} \mathrm{C}$ & 0.580 & 0.404 \\
\hline$E^{*} @-40^{\circ} \mathrm{C}$ & -0.552 & $-0.994++$ \\
$E^{*} @-30^{\circ} \mathrm{C}$ & -0.364 & $-0.976++$ \\
$E^{*} @-20^{\circ} \mathrm{C}$ & -0.194 & $-0.925++$ \\
$E^{*} @-10^{\circ} \mathrm{C}$ & -0.073 & $-0.730+$ \\
$E^{*} @-0^{\circ} \mathrm{C}$ & 0.010 & -0.013 \\
$E^{*} @ 10^{\circ} \mathrm{C}$ & 0.041 & 0.386 \\
$E^{*} @ 20^{\circ} \mathrm{C}$ & 0.052 & 0.488 \\
\hline
\end{tabular}

+ :over ${ }_{1}^{\prime} 0.6_{1}^{\prime},++$ :over ${ }_{1}^{\prime} 0.81$ 


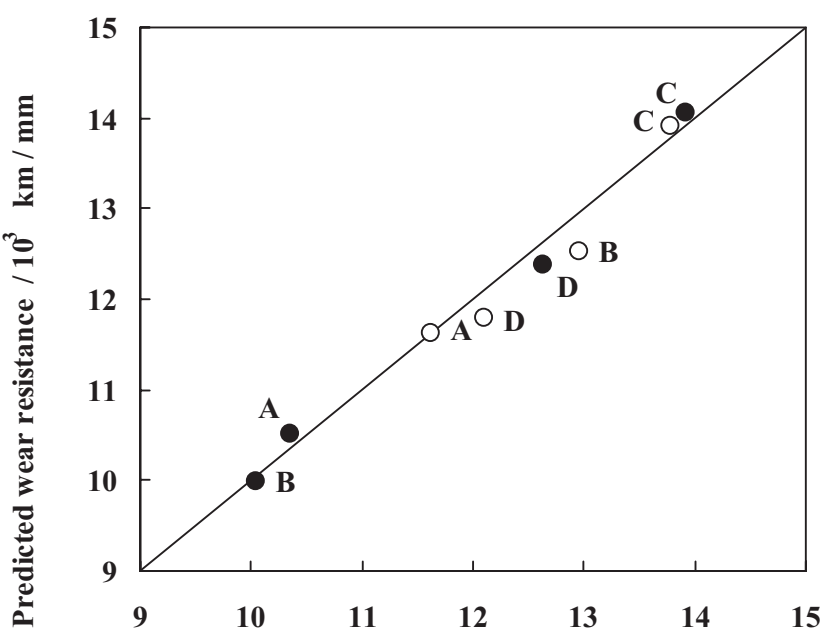

Observed wear resistance $/ 10^{3} \mathrm{~km} / \mathrm{mm}$

Figure 6 Correlation between predicted wear resistance and observed wear resistance of rubber compound A-D in (O) summer and

winter.

摩耗性能結果はー40 ㅇゴムの特性で, 夏期の摩耗性能 結果は0 ${ }^{\circ} \mathrm{C}$ のゴムの特性を指標にできることが示された. また，冬期の結果では破壊エネルギーおよび貯蔵弾性率 $E^{*}$ 両者の耐摩耗性能係数に対する相関係数は高いが，夏 期の結果においては, 破壊エネルギーの耐摩耗性能係数に 対する相関係数が高いことが明らかになった。これは夏期 においては $0{ }^{\circ} \mathrm{C}$ 付近の物性が影響すると考えられるが，そ

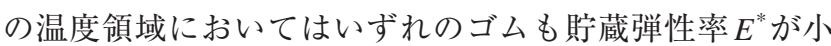
さくなっており，相対的に耐摩耗係数に対して破壊エネル ギーの寄与が大きくなったためと考えられる.

以上のことから，ゴムの摩耗現象は

1）ゴムの低温物性と相関があること。

2）ゴムの破壊エネルギー $F$ と貯蔵弾性率 $E^{*}$ が関与してい ること.

3）環境温度により破壊エネルギーの寄与と貯蔵弾性率 $E^{*}$ の寄与が変化すること

が明らかになった。
Table 4 Parameter of wear resistance as a function of fracture energy $F$ and storage modulus $E^{*}$ in equation (5) and the correlation coefficient between calculated and observed data for rubber compounds A-D.

\begin{tabular}{ccccc}
\hline Condition & $\mathrm{a}$ & $\mathrm{b}$ & $\mathrm{c}$ & $\mathrm{R}$ \\
\hline Summer & 0.811 & 0.250 & 7.179 & $0.997++$ \\
Winter & 0.025 & 0.162 & 10.448 & $0.994++$ \\
\hline
\end{tabular}

5. 結

論

同一車両にて異なる路面温度での摩耗性能を測定した結 果，摩耗は夕イヤ配合の温度依存性に影響を受けることが 示された。この際，耐摩耗性能係数 $W$ は, 低温のゴムの 破壊エネルギーF $\left(\mathrm{MJ} / \mathrm{m}^{3}\right)$ および貯蔵弾性率 $E^{*}(\mathrm{~Pa})$ との間に関連があり, 次の関数でスケーリングできること が明らかになった。

$W=c\left(F^{a} / E^{*}{ }^{b}\right) \quad(a, b, c$ は定数 $)$

また，環境温度が変化するとそれぞれの物性值に温度依存 性があり，摩耗への寄与が変化した。

\section{References}

1 ) Grosch, K. A.; Schallamach, A.: Wear, 4, 356 (1961)

2 ) Grosch, K. A.: Rubber Chem. Technol., 69, 495 (1996)

3 ) Mouri, H.: Zairyo Kagaku, 34, 25 (1997)

4 ) Uchiyama, Y.: Nippon Gomu Kyokaishi, 80, 120 (2007)

5 ) Kienle, R. N.; Dizon, E. S.: Rubber Chem. Technol., 44, 996 (1971)

6 ) Veith, A. G.: Polymer Testing, 7, 177 (1987)

7 ) Moore, D. F.; Geyer, W.: Wear, 22, 113 (1972)

8 ) Grosch, K. A.; Schallamach, A.: Rubber Chem. Technol., 39, 287 (1966)

9 ) Gent, A. N.; Pulford, C. T. R.: J. Appl. Polym. Sci., 28, 943 (1983)

10) Saito, Y.: Kautschuk Gummi Kunststoffe, 39, 30（1986）

11) Grosch, K. A.: Rubber Chem. Technol., 37, 386 (1964)

12) Mukherjee, S. N.; Basu, S. K.: Int. J. Mach. Tool Des. Res., 7, 15 (1967)

\section{日本語表記参考文献}

3 ) 毛利 浩: 材料科学, 34, 25 (1997)

4 ）内山吉隆：日本ゴム協会誌，80,120（2007） 